\title{
Obesity in work-up of kidney transplant candidates - review of clinical practice guidelines
}

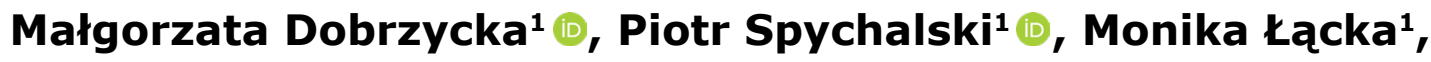 \\ Monika Proczko-Stepaniak ${ }^{\circledR}{ }^{\circledR}$, Alicja Dębska-Ślizień ${ }^{3}{ }^{\circledR}$,
}

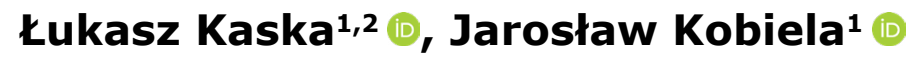

${ }^{1}$ Department of General, Endocrine and Transplant Surgery, Medical University of Gdańsk, Poland
${ }^{2}$ Department of General Surgery, Medical University of Gdańsk, Poland
${ }^{3}$ Department of Nephrology, Transplantology and Internal Diseases, Medical University of Gdańsk, Poland

\begin{abstract}
Background: Incidence of morbid obesity is rising worldwide. Current clinical practice guidelines for the pre-transplant evaluation of end-stage kidney disease (ESKD) patients lack clear recommendations on morbid obesity. Material and methods: The aim of this review was to summarize the current guidelines on the role and treatment of obesity in kidney transplant recipients. Eight current national and international clinical practice guidelines were identified in a comprehensive literature search. Results: All guidelines underline early detection of obesity and obesity-related comorbidities in ESKD patients. Only two guidelines explored the role of weight-loss surgery, however due to the lack of sufficient evidence no formal recommendation of surgical procedure was given. Conclusions: Diagnosis and treatment of obesity remains underappreciated in the current guidelines, most of which do not include pharmacological and surgical interventions. High-quality evidence is warranted to assess the role of weight-loss including surgery in ESKD patients and to update the recommendations in future guidelines.
\end{abstract}

Keywords: obesity $\cdot$ end-stage kidney disease $\cdot$ bariatric surgery

\section{Citation}

Dobrzycka M, Spychalski P, Łącka M, Proczko-Stepaniak M, Kaska Ł, Dębska-Ślizień A, Kobiela J. Obesity in work-up of kidney transplant candidates - review of clinical practice guidelines. Eur J Transl Clin Med. 2020;3(2):72-79.

DOI: $10.31373 /$ ejtcm/128771

\section{Corresponding author:}

Małgorzata Dobrzycka, Department of General, Endocrine and Transplant Surgery, Medical University of Gdańsk, Gdańsk, Poland

e-mail: malgorzata.dobrzycka@gumed.edu.pl

No external funds.

Available online: www.ejtcm.gumed.edu.pl

$\prod_{\text {TRANSPARENT }}^{2}$

Copyright ${ }^{\circledR}$ Medical University of Gdańsk

This is Open Access article distributed under the terms of the Creative Commons Attribution-ShareAlike 4.0 International. 


\section{Introduction}

The number of obese and morbidly obese end-stage kidney disease (ESKD) patients is rising. Due to the obesity epidemic, nearly $60 \%$ of all kidney transplant recipients are overweight or obese, with male predominance [1]. Kidney transplantation (KT) is the most effective method of ESKD treatment but it is still a debatable whether obese patients are suitable candidates for KT [2-6]. Clinical practice guidelines (CPGs) review current research and formulate recommendations based on available evidence and expert opinion. Clear guidance regarding obesity assessment and treatment options would be an essential part for the selection process of candidates for KT. The aim of this review is to assess the availability, quality, and consistency of recommendations for obesity evaluation and treatment before KT included in current national and international CPGs for kidney transplant candidates.

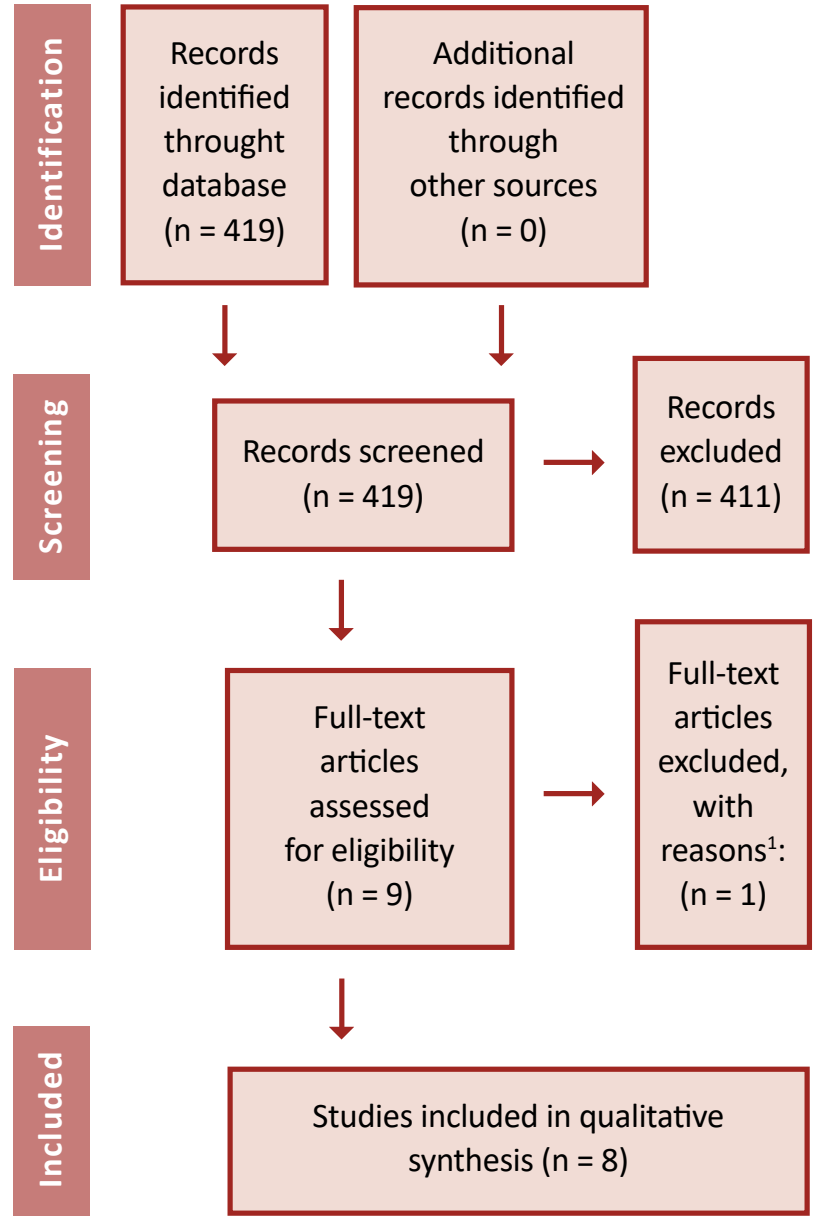

Figure 1. PRISMA flowchart. ${ }^{1}$ Clinical Practice Guideline excluded due to lack of recommendation for inclusion to kidney transplantation [7].

\section{Material and methods}

A systematic review was performed according to Preferred Recording Items for Systematic Review and Meta-Analyses (PRISMA) guidelines [7]. The search strategy included literature published until January 2020, using the following search query: ("kidney transplantation" OR ("kidney" AND "transplantation" OR "kidney transplantation" OR ("kidney" AND "transplant") OR "kidney transplant") AND ("Assessment") AND ("guideline" OR "guidelines"). Two researches independently searched and assessed the guidelines. We included only CPGs for the selection of candidates for deceased donor kidney transplantation. CPG for living donor kidney transplantation were excluded after screening due to identification of recommendation for obesity only in kidney donors [89]. The study protocol was presented in PRISMA flowchart (Figure 1). The following data were extracted: society, year of publication, inclusion of obesity into recommendation, recommendations for obesity treatment and grade of evidence.

\section{Results}

The literature search revealed 419 articles. A total of 411 were excluded during screening of titles and abstracts. The remaining $8 \mathrm{CPG}$ were searched for obesity evaluation recommendations. Key facts about the included studies are summarized in Table 1.

\section{Recommendations for obesity evaluation before kidney transplantation}

Three CPGs recommended that obesity should be routinely assessed at each pre-transplant consultation [10-12]. The included measurements should be as follows: patients height, weight, calculation of BMI. Additionally, waist circumference should be assessed when weight and physical appearance suggest obesity, but calculated BMI is $<35 \mathrm{~kg} / \mathrm{m}^{2}$ [10]. The definition of obesity in adults includes waist circumference $\geq 102 \mathrm{~cm}$ in men and $\geq 88 \mathrm{~cm}$ in women [11]. Two guidelines recommended weight reduction before transplantation if BMI exceeds $30 \mathrm{~kg} / \mathrm{m}^{2}$ [12-13]. One study set the upper limit of BMI to $40 \mathrm{~kg} / \mathrm{m}^{2}$ [14]. Another CGP states that in patients with $\mathrm{BMI}>36$ $\mathrm{kg} / \mathrm{m}^{2}$ the transplantation is associated with an unacceptably high risk of death and needs careful consideration [12]. All CPGs state that obesity of the kidney recipient byitself is not a contraindication for $\mathrm{KT}$, however if co-existing with other comorbidities (e.g. advanced cardiovascular diseases, peripheral vascular 
Table 1. Obesity in current clinical practice guidelines

\begin{tabular}{|c|c|c|c|}
\hline Guidelines & Region & $\begin{array}{l}\text { Obesity in candidates for } \\
\text { transplantation }\end{array}$ & Recommendation in obesity \\
\hline AST (2001) & USA & $\begin{array}{l}\text { Obesity without comorbidities* } \\
\text { is not a contraindication for KT } \\
\text { (Level of evidence not provided). }\end{array}$ & $\begin{array}{c}\text { Weight reduction } \\
\text { (role of limited exercise in dialyzed patients) } \\
\text { (Level of evidence not provided). }\end{array}$ \\
\hline $\begin{array}{c}\text { Canadian Society } \\
\text { of Transplantation } \\
\text { (2005) }\end{array}$ & Canada & $\begin{array}{l}\text { Obesity without comorbidities is } \\
\text { not a contraindication } \\
\text { for KT (Grade C). } \\
\text { In patients with } \\
\text { BMI }>36 \mathrm{~kg} / \mathrm{m}^{2} \mathrm{KT} \\
\text { is contraindicated. }\end{array}$ & $\begin{array}{l}\text { - Weight reduction to } \mathrm{BMI}<30 \mathrm{~kg} / \mathrm{m}^{2} \\
\text { - Surgical intervention for obesity may be } \\
\text { considered in extreme cases (Grade B) }\end{array}$ \\
\hline $\begin{array}{l}\text { Bunnapradist } \\
\text { \& Danovich } \\
(2007)\end{array}$ & USA & $\begin{array}{l}\text { In patients with } \\
\text { BMI }>40 \mathrm{~kg} / \mathrm{m}^{2} \mathrm{KT} \\
\text { contraindicated. }\end{array}$ & $\begin{array}{l}\text { Weight reduction } \\
\text { (the benefit is unclear, method not specified) } \\
\text { (Level of evidence not provided). }\end{array}$ \\
\hline $\begin{array}{l}\text { Lisbon Conference } \\
\text { Report } \\
(2007)\end{array}$ & Europe & $\begin{array}{c}\text { In morbidly obese } \\
\text { KT is contraindicated } \\
\text { (BMI not applicable) } \\
\text { (Level of evidence not provided). }\end{array}$ & No recommendation \\
\hline KDIGO (2009) & $\begin{array}{l}\text { Interna- } \\
\text { tional }\end{array}$ & $\begin{array}{c}\text { In patients with BMI > } 30 \mathrm{~kg} / \\
\mathrm{m}^{2} \mathrm{KT} \text { is contraindicated. }\end{array}$ & $\begin{array}{l}\text { - Early diagnosis of obesity } \\
\text { (Level of evidence not provided). } \\
\text { - Obese individuals should be offered } \\
\text { a weight-reduction programme } \\
\text { (Level of evidence not provided). } \\
\text { - Diet and other behavior modifications } \\
\text { are safe in KT recipients } \\
\text { (Level of evidence not provided. } \\
\text { - Bariatric surgery may be performed } \\
\text { safely in selected KT recipients } \\
\text { (Level of evidence not provided). }\end{array}$ \\
\hline KHA-CARI (2013) & Australia & No recommendation & $\begin{array}{l}\text { - Obesity should be assessed at each } \\
\text { visit (Grade C). } \\
\text { - Diet and behavioral modification } \\
\text { are likely to be safe. } \\
\text { Diet that is individually planned with } \\
\text { a moderate energy restriction of about } \\
30 \% \text { of energy expenditure, } \\
\text { with monthly follow up with a dietician } \\
\text { (Level of evidence not provided). } \\
\text { - There is insufficient evidence to make } \\
\text { recommendations or suggestions with } \\
\text { respect to bariatric surgery } \\
\text { (Level of evidence not provided). }\end{array}$ \\
\hline $\begin{array}{l}\text { European Renal Best } \\
\text { Practice Guideline } \\
\text { (2015) }\end{array}$ & Europe & $\begin{array}{c}\text { BMI }>30 \mathrm{~kg} / \mathrm{m}^{2} \\
\text { is a contraindication for } \mathrm{KT} \\
\text { (Level of evidence not provided). }\end{array}$ & $\begin{array}{l}\text { Obese patients should } \\
\text { reduce weight before KT } \\
\text { (Level of evidence not provided). }\end{array}$ \\
\hline
\end{tabular}

*advanced cardiovascular, peripheral vascular, liver or pulmonary disease, HIV, active hepatitis, active pulmonary or systemic tuberculosis 
diseases, liver or pulmonary disease, active hepatitis) it increases the risk of perioperative complications and may impair graft and patient survival $[12,15]$.

\section{Recommendations for diet and behavioral therapy}

These therapies were considered safe in ESKD population but they were related only to a short-term weight reduction [10]. Only one study clearly stated that overweight kidney transplant recipients should have an individually-planned diet with a moderate energy restriction of about $30 \%$ of energy expenditure, with dietician follow-up [11]. It recommended also to create a caloric deficit of 500-1000 kcal/day along with increased physical activity [11].

\section{Recommendations for pharmacological obesity therapies}

The analyzed CPGs briefly discussed the role and the risk of novel pharmacological weight reduction therapies [10-11]. There were no trials examining the safety of those interventions in this specific population. Two medications (orlistat and sibutramine) were mentioned in recommendations [10-11]. Orlistat is related to decreased absorption of fat-soluble vitamins and may also interfere with the absorption of immunosuppressive medications and may be associated with higher risk in ESKD patients [10]. Sibutramine may increase blood pressure and heart rate and is not advised in patients with cardiovascular risk [10].

\section{Recommendations for bariatric surgery}

Little was mentioned about bariatric surgery in the current CPGs. Two of eight CPGs recommend weight-loss surgery before kidney transplantation [1011]. However, the quality of existing evidence was insufficient to form recommendations about qualification, procedure type or procedure timing (i.e. before or after the $\mathrm{KT}$ ).

\section{Discussion}

The prevalence of obesity among patients with ESKD continues to increase. Obesity was shown to be an independent risk factor not only of the ESKD development but also to accelerate the progression of that disease [5]. Kidney transplantation is considered as gold standard in ESKD treatment. Obesity is now limiting the access to KT by delaying the enrollment to transplant list and prolonging the waiting time com- pared to the nonobese candidates [16-17]. Additionally, obesity is associated with inferior short-term results of transplantation $[3,5]$.

Current CPGs are consistent regarding a strong need of early obesity assessment before enrollment to transplant waiting list. Most guidelines use BMI to assess obesity for waiting listing purposes $[10,13,18]$. $\mathrm{BMI}<30 \mathrm{~kg} / \mathrm{m}^{2}$ prior transplantation is recommended but in some studies BMI below $35 \mathrm{~kg} / \mathrm{m}^{2}$ is considered a selection criterion [19-20]. The limitations of BMI as a metric of body fat must be appreciated. Anthropometric measures (waist circumference and waist-to-hip ratio (WHR)) are considered as an alternative to $\mathrm{BMI}$ in body composition assessment. These measures were shown to have a direct association with increased cardiovascular mortality in dialyzed ESKD patients as well as post-transplant mortality more precisely than BMI [21-22]. The existing guidelines are based on available original studies at the time of their publication. All current clinical practice guidelines were published before 2015. The role of diet and pharmacological treatment was poorly discussed but the level of evidence is sufficient to consider them safe for kidney transplant candidates [10-11]. The surgical treatment of obesity was not included in most CPGs due to limited evidence on safety and outcomes of bariatric procedures at the time of their publication. Only two CPGs mentioned possible implementation of bariatric surgery in that indication [11-12]. Since then several large studies were published giving new insights into the management of obese ESKD patients [23-25]. The results of these studies are presented below. It is likely that these data will be included in new editions of CPGs.

Based on the current knowledge, the use of pharmacological interventions for the treatment of obesity is limited in ESKD patients. First, orlistat use in patients with chronic disease is contraindicated because of its association with acute kidney injury and chronic kidney disease due to increased absorption of oxalate and the risk of nephrocalcinosis, inflammation and kidney fibrosis as a result [26-28]. Moreover, post-transplant drug interaction, particularly with cyclosporin, results in reducing their bioavailability and limits its use [29]. Secondly, sibutramine was withdrawn from the obesity treatment due to unacceptable increased cardiovascular risk [30]. A newer drug lorcaserin, is associated with potential kidney benefit, but limited to the lower risk of new-onset of albuminuria. Its use in ESKD patients is contraindicated due to worsening of chronic kidney disease stage [31-32]. Bupropion, likewise, should not be used in ESKD patients [32-33].

The role of physical activity was discussed in only one guideline [11]. Research has shown that pre- 
-transplant aerobic exercise, long-term progressive resistance exercise, resistance training, and home-based exercise are tolerable in patients with ESKD [3435]. Interestingly, the aerobic exercise is not related to weight reduction but has an positive impact on dialyzed patients' quality of life [36]. After transplantation, aerobic exercise, resistance training and individualized progressive exercise programs are effective in weight-loss programs [34].

Feasibility and safety of bariatric surgery is currently investigated and discussed. A recent study has shown an increasing number of patients with ESKD undergoing bariatric surgery as a bridge to KT [23]. Nevertheless, no consensus was reached regarding the management options for obese KT candidates. It was previously believed that bariatric surgery use in ESKD patients may be limited because of higher mortality risk. However the safety and significance of weight loss surgery in ESKD patients increased over the years [25, 37-39]. Two bariatric procedures were preferred $[23,40]$. LSG (laparoscopic sleeve gastrectomy) and LRYGB (laparoscopic roux-en-y gastric bypass) appear to cause effective weight-loss before KT and improve surgical access during transplantation [41-42]. Uncertainties exist regarding optimal timing of bariatric surgery [38]. It has not been proven yet if the bariatric procedure should be performed before or after engraftment. Both approaches are related to low risk of graft failure and low mortality in long-term analysis when compared to the mortality rate of obese patients without ESKD [43]. Complication rates of LSG were similar between patients with and without ESKD $[23,44]$. It should be noticed that LSG performed before transplantation is associated with significant changes of pharmacokinetics of tacrolimus and mycophenolate mofetil (increased maximal concentration and decreased clearance) in that group of patients [45]. Whereas malabsorptive procedures are related to hyperoxaluria and increased risk of nephrolithiasis [46].

Interestingly, an obesity paradox was described in dialyzed patients [47-48]. It is associated with better survival of obese patients who were transplanted than all patients who stay on transplant waiting list. Howver these results may be confounded by worse outcome of malnourished ESKD patients [47, 49-50]. Moreover, obesity reduces the likelihood of being enrolled to the waiting list, but not the transplantation once enrolled, especially among women [17].

Recent large metanalyses support higher risk of KT of obese patients and better survival in lower BMI patients [51-53]. It was proven that kidney recipients have an inferior survival when their BMI is $>40 \mathrm{~kg} / \mathrm{m}^{2}$
$[19,54]$. Recent metanalysis (of 209,000 patients) revealed lower mortality, delayed graft function (DGF), acute rejection, infectious complication rate and better 1-, 2- and 3-year survival in kidney recipients with $\mathrm{BMI}<30 \mathrm{~kg} / \mathrm{m}^{2}$ [52]. In another metanalysis (17 studies, 138081 patients) obesity was demonstrated not to be related with higher mortality risk but was associated with higher risk of graft loss and DGF [53]. A metanalysis of 9296 patients confirmed higher risk of DGF but not acute rejection and death risk [55]. The results of those analyses support the necessity of obesity treatment in ESKD patients. Several studies investigated the benefits and risk of bariatric surgery in that group of patients [24, 56-58]. Laparoscopic SG has replaced Roux-en-Y gastric bypass (RYGB) as the most common bariatric surgical procedure in patients with ESKD [23]. SG in ESKD patients is not related to higher risk of leaks, reoperations, or mortality in 1 year follow-up [59]. Our center morbidly obese ESKD patients have similar weight loss results after bariatric procedure than non-ESKD $[42,44]$. Nine of twenty of them underwent kidney transplantation without any perioperative complications and with good kidney function in follow-up. Patients who underwent KT after SG have good 1-year and long term transplantation results in small group analysis [58]. Morbidly obese patients after LSG experienced lower rates of DGF and readmission related to graft insufficiency in 1 year follow-up [58]. The mortality rate of obese individuals with ESKD after SG is lower (1.8/100 patient-years compared to 7.3 in the control group) [60]. Moreover, in stage 3 CKD significant improvement of kidney function was observed [60]. The emerging evidence from those studies supports the low risk and safety of bariatric surgery in ESKD patient.

\section{Conclusion}

In conclusion, the obesity epidemic has major implications on kidney transplant candidates' evaluation. In existing CPGs there is a consensus regarding the need of obesity assessment in transplant candidates. However, most of the evaluated CPGs are inconclusive concerning the role of pharmacological and surgical interventions for the treatment of obesity. New large-scale studies seem to be the missing link that suggests clear recommendations for obese patients' management. It seems necessary to update the guidelines with results of recent studies on the new measures in the assessment of obesity and its treatment, with special attention to surgical treatment. 


\section{References}

1. Friedman AN, Miskulin DC, Rosenberg IH, Levey AS. Demographics and trends in overweight and obesity in patients at time of kidney transplantation. Am J Kidney Dis [Internet]. 2003 Feb;41(2):480-7. Available from: https://linkinghub. elsevier.com/retrieve/pii/S0272638602691619

2. MacLaughlin HL, Campbell KL. Obesity as a barrier to kidney transplantation: Time to eliminate the body weight bias? Semin Dial [Internet]. 2019 May 2;32(3):219-22. Available from: https://onlinelibrary.wiley.com/doi/abs/10.1111/sdi.12783

3. Di Cocco P, Okoye O, Almario J, Benedetti E, Tzvetanov IG, Spaggiari M. Obesity in kidney transplantation. Transpl Int [Internet]. 2020 Jun 19;33(6):581-9. Available from: https://onlinelibrary.wiley.com/doi/abs/10.1111/tri.13547

4. Kaballo MA, Canney M, O'Kelly P, Williams Y, O'Seaghdha CM, Conlon PJ. A comparative analysis of survival of patients on dialysis and after kidney transplantation. Clin Kidney J [Internet]. 2018 Jun 1;11(3):389-93. Available from: https:// academic.oup.com/ckj/article/11/3/389/4557548

5. Lakkis JI, Weir MR. Obesity and Kidney Disease. Prog Cardiovasc Dis [Internet]. 2018 Jul;61(2):157-67. Available from: https://linkinghub.elsevier.com/retrieve/pii/S0033062018301282

6. Toapanta-Gaibor NG, Suñer-Poblet M, Cintra-Cabrera M, Pérez-Valdivia MÁ, Suárez-Benjumea A, Gonzalez-Roncero FM, et al. Reasons for Noninclusion on the Kidney Transplant Waiting List: Analysis in a Set of Hemodialysis Centers. Transplant Proc [Internet]. 2018 Mar;50(2):553-4. Available from: https://linkinghub.elsevier.com/retrieve/pii/S0041134517309338

7. Moher D, Liberati A, Tetzlaff J, Altman DG. Preferred Reporting Items for Systematic Reviews and Meta-Analyses: The PRISMA Statement. PLoS Med [Internet]. 2009 Jul 21;6(7):e1000097. Available from: https://dx.plos.org/10.1371/journal.pmed.1000097

8. Mandelbrot DA, Reese PP, Garg N, Thomas CP, Rodrigue JR, Schinstock C, et al. KDOQI US Commentary on the 2017 KDIGO Clinical Practice Guideline on the Evaluation and Care of Living Kidney Donors. Am J Kidney Dis [Internet]. 2020 Mar;75(3):299-316. Available from: https://linkinghub.elsevier.com/retrieve/pii/S0272638619311175

9. Andrews PA, Burnapp L. British Transplantation Society / Renal Association UK Guidelines for Living Donor Kidney Transplantation 2018. Transplantation [Internet]. 2018 Jul;102(7):e307. Available from: http://journals.Iww.com/00007890-201807000-00010

10. Kidney Disease: Improving Global Outcomes (KDIGO) Transplant Work Group. Special Issue: KDIGO Clinical Practice Guideline for the Care of Kidney Transplant Recipients. Am J Transplant [Internet]. 2009 Nov;9(Suppl 3):S1-155. Available from: http://doi.wiley.com/10.1111/j.1600-6143.2009.02834.x

11. Jardine M, Commons RJ, de Zoysa JR, Wong MG, Gilroy N, Green J, et al. Kidney Health Australia - Caring for Australasians with Renal Impairment guideline recommendations for infection control for haemodialysis units. Nephrology [Internet]. 2019 Apr 29;nep.13511. Available from: https://onlinelibrary.wiley.com/doi/abs/10.1111/nep.13511

12. Knoll G, Cockfield S, Blydt-Hansen T, Baran D, Kiberd B, Landsberg D, et al. Canadian Society of Transplantation: consensus guidelines on eligibility for kidney transplantation. CMAJ [Internet]. 2005 Nov 8;173(10):S1-25. Available from: http://www.ncbi.nlm.nih.gov/pubmed/16275956

13. Abramowicz D, Cochat P, Claas FHJ, Heemann U, Pascual J, Dudley C, et al. European Renal Best Practice Guideline on kidney donor and recipient evaluation and perioperative care: FIGURE 1. Nephrol Dial Transplant [Internet]. 2015 Nov;30(11):1790-7. Available from: https://academic.oup.com/ndt/article-lookup/doi/10.1093/ndt/gfu216

14. Bunnapradist S, Danovitch GM. Evaluation of Adult Kidney Transplant Candidates. Am J Kidney Dis [Internet]. 2007 Nov;50(5):890-8. Available from: https://linkinghub.elsevier.com/retrieve/pii/S027263860701147X

15. Abbud-Filho M, Adams PL, Alber J, Cardella C, Chapman J, Cochat P, et al. A Report of the Lisbon Conference on the Care of the Kidney Transplant Recipient. Transplantation [Internet]. 2007 Apr;83(Supplement):S1-22. Available from: http:// journals.Iww.com/00007890-200704271-00001

16. Lassalle M, Fezeu LK, Couchoud C, Hannedouche T, Massy ZA, Czernichow S. Obesity and access to kidney transplantation in patients starting dialysis: A prospective cohort study. Aguilera Al, editor. PLoS One [Internet]. 2017 May 11;12(5):e0176616. Available from: https://dx.plos.org/10.1371/journal.pone.0176616

17. Ladhani M, Craig JC, Wong G. Obesity and gender-biased access to deceased donor kidney transplantation. Nephrol Dial Transplant [Internet]. 2019 Jun 15;35(1):184-9. Available from: https://academic.oup.com/ndt/advance-article/ doi/10.1093/ndt/gfz100/5519371

18. Maggiore U, Abramowicz D, Budde K, Crespo M, Mariat C, Oberbauer R, et al. Standard work-up of the low-risk kidney transplant candidate: a European expert survey of the ERA-EDTA Developing Education Science and Care for Renal Transplantation in European States Working Group. Nephrol Dial Transplant [Internet]. 2019 Sep 1;34(9):1605-11. Available from: https://academic.oup.com/ndt/article/34/9/1605/5281215

19. Lentine KL, Delos Santos R, Axelrod D, Schnitzler MA, Brennan DC, Tuttle-Newhall JE. Obesity and Kidney Transplant Candidates: How Big Is Too Big for Transplantation. Am J Nephrol [Internet]. 2012 Dec;36(6):575-86. Available from: https:// www.karger.com/Article/FullText/345476 
20. Tran $\mathrm{M}-\mathrm{H}$, Foster $\mathrm{CE}$, Kalantar-Zadeh K, Ichii $\mathrm{H}$. Kidney transplantation in obese patients. World J Transplant [Internet]. 2016;6(1):135. Available from: http://www.wjgnet.com/2220-3230/full/v6/i1/135.htm

21. Kramer H, Gutiérrez OM, Judd SE, Muntner P, Warnock DG, Tanner RM, et al. Waist Circumference, Body Mass Index, and ESRD in the REGARDS (Reasons for Geographic and Racial Differences in Stroke) Study. Am J Kidney Dis [Internet]. 2016 Jan;67(1):62-9. Available from: https://linkinghub.elsevier.com/retrieve/pii/s0272638615008550

22. Kovesdy C, Furth S, Zoccali C, World Kidney Day. Obesity and kidney disease: Hidden consequences of the epidemic. Indian J Nephrol [Internet]. 2017 Mar;27(2):85. Available from: http://www.indianjnephrol.org/text.asp?2017/27/2/85/201691

23. Sheetz KH, Woodside KJ, Shahinian VB, Dimick JB, Montgomery JR, Waits SA. Trends in Bariatric Surgery Procedures among Patients with ESKD in the United States. Clin J Am Soc Nephrol [Internet]. 2019 Aug 7;14(8):1193-9. Available from: https://cjasn.asnjournals.org/lookup/doi/10.2215/CJN.01480219

24. Bouchard P, Tchervenkov J, Demyttenaere S, Court O, Andalib A. Safety and efficacy of the sleeve gastrectomy as a strategy towards kidney transplantation. Surg Endosc [Internet]. 2020 Jun;34(6):2657-64. Available from: http://link.springer. com/10.1007/s00464-019-07042-z

25. Gazzetta PG, Bissolati M, Saibene A, Ghidini CGA, Guarneri G, Giannone F, et al. Bariatric Surgery to Target Obesity in the Renal Transplant Population: Preliminary Experience in a Single Center. Transplant Proc [Internet]. 2017 May;49(4):6469. Available from: https://linkinghub.elsevier.com/retrieve/pii/S0041134517301677

26. Padwal RS, Rucker D, Li SK, Curioni C, Lau DC. Long-term pharmacotherapy for obesity and overweight. Cochrane Database Syst Rev [Internet]. 2003 Oct 20; Available from: http://doi.wiley.com/10.1002/14651858.CD004094.pub2

27. Solomon LR, Nixon AC, Ogden L, Nair B. Orlistat-induced oxalate nephropathy: an under-recognised cause of chronic kidney disease. BMJ Case Rep [Internet]. 2017 Nov 12;2017:bcr-2016-218623. Available from: https://casereports.bmj. com/lookup/doi/10.1136/bcr-2016-218623

28. Humayun Y, Ball KC, Lewin JR, Lerant AA, Fülöp T. Acute oxalate nephropathy associated with orlistat. J Nephropathol [Internet]. 2016 Mar 29;5(2):79-83. Available from: http://nephropathol.com/Abstract/JNP 20160410110202

29. Beyea MM, Garg AX, Weir MA. Does orlistat cause acute kidney injury? Ther Adv Drug Saf [Internet]. 2012 Apr 23;3(2):537. Available from: http://journals.sagepub.com/doi/10.1177/2042098611429985

30. Vanholder R, Van Laecke S, Glorieux G, Verbeke F, Castillo-Rodriguez E, Ortiz A. Deleting Death and Dialysis: Conservative Care of Cardio-Vascular Risk and Kidney Function Loss in Chronic Kidney Disease (CKD). Toxins (Basel) [Internet]. 2018 Jun 12;10(6):237. Available from: http://www.mdpi.com/2072-6651/10/6/237

31. Scirica BM, Bohula EA, Dwyer JP, Qamar A, Inzucchi SE, McGuire DK, et al. Lorcaserin and Renal Outcomes in Obese and Overweight Patients in the CAMELLIA-TIMI 61 Trial. Circulation [Internet]. 2019 Jan 15;139(3):366-75. Available from: https://www.ahajournals.org/doi/10.1161/CIRCULATIONAHA.118.038341

32. Navaneethan SD. Trials and Tribulations in Studying Kidney Outcomes With Intentional Weight Loss. Circulation [Internet]. 2019 Jan 15;139(3):376-9. Available from: https://www.ahajournals.org/doi/10.1161/CIRCULATIONAHA.118.038677

33. Turpeinen M, Koivuviita N, Tolonen A, Reponen $\mathrm{P}$, Lundgren S, Miettunen J, et al. Effect of renal impairment on the pharmacokinetics of bupropion and its metabolites. Br J Clin Pharmacol [Internet]. 2007 Aug;64(2):165-73. Available from: http://doi.wiley.com/10.1111/i.1365-2125.2007.02866.x

34. Luan X, Tian X, Zhang H, Huang R, Li N, Chen P, et al. Exercise as a prescription for patients with various diseases. J Sport Heal Sci [Internet]. 2019 Sep;8(5):422-41. Available from: https://linkinghub.elsevier.com/retrieve/pii/S2095254619300493

35. Van Huffel L, Tomson CR V., Ruige J, Nistor I, Van Biesen W, Bolignano D. Dietary Restriction and Exercise for Diabetic Patients with Chronic Kidney Disease: A Systematic Review. Norata GD, editor. PLoS One [Internet]. 2014 Nov 25;9(11):e113667. Available from: https://dx.plos.org/10.1371/journal.pone.0113667

36. Sigal RJ, Kenny GP, Boulé NG, Wells GA, Prud'homme D, Fortier M, et al. Effects of Aerobic Training, Resistance Training, or Both on Glycemic Control in Type 2 Diabetes. Ann Intern Med [Internet]. 2007 Sep 18;147(6):357. Available from: http://annals.org/article.aspx?doi=10.7326/0003-4819-147-6-200709180-00005

37. Chang AR, Grams ME, Navaneethan SD. Bariatric Surgery and Kidney-Related Outcomes. Kidney Int Reports [Internet]. 2017 Mar;2(2):261-70. Available from: https://linkinghub.elsevier.com/retrieve/pii/s2468024917300128

38. Erickson KF, Navaneethan SD. Bariatric Surgery for ESKD Patients. Clin J Am Soc Nephrol [Internet]. 2019 Aug 7;14(8):11257. Available from: https://cjasn.asnjournals.org/lookup/doi/10.2215/CJN.07350619

39. Tran M-H, Foster CE, Kalantar-Zadeh K, Ichii H. Kidney transplantation in obese patients. World J Transplant [Internet]. 2016 Mar;6(1):135. Available from: http://www.wignet.com/2220-3230/full/v6/i1/135.htm

40. Mahawar KK, Parmar C, Graham Y. Procedure and patient selection in bariatric and metabolic surgery. Minerva Chir [Internet]. 2019 Dec;74(5). Available from: https://www.minervamedica.it/index2.php?show=R06Y2019N05A0407

41. Al-Bahri S, Fakhry TK, Gonzalvo JP, Murr MM. Bariatric Surgery as a Bridge to Renal Transplantation in Patients with End-Stage Renal Disease. Obes Surg [Internet]. 2017 Nov 13;27(11):2951-5. Available from: http://link.springer.com/10.1007/s11695-017-2722-6 
42. Dobrzycka M, Proczko-Stepaniak M, Kaska Ł, Wilczyński M, Dębska-Ślizień A, Kobiela J. Weight Loss After Bariatric Surgery in Morbidly Obese End-Stage Kidney Disease Patients as Preparation for Kidney Transplantation. Matched Pair Analysis in a High-Volume Bariatric and Transplant Center. Obes Surg [Internet]. 2020 Jul 5;30(7):2708-14. Available from: http://link.springer.com/10.1007/s11695-020-04555-8

43. Cohen JB, Lim MA, Tewksbury CM, Torres-Landa S, Trofe-Clark J, Abt PL, et al. Bariatric surgery before and after kidney transplantation: long-term weight loss and allograft outcomes. Surg Obes Relat Dis [Internet]. 2019 Jun;15(6):935-41. Available from: https://linkinghub.elsevier.com/retrieve/pii/S1550728919301327

44. Proczko M, Kaska $Ł$, Kobiela J, Stefaniak T, Zadrożny D, Śledziński Z. Bariatric surgery in morbidly obese patients with chronic renal failure, prepared for kidney transplantation - case reports. Polish J Surg [Internet]. 2013 Jan 1;85(7):40711. Available from: http://www.degruyter.com/view/i/pjs.2013.85.issue-7/pjs-2013-0062/pjs-2013-0062.xml

45. Chan G, Hajjar R, Boutin L, Garneau PY, Pichette V, Lafrance J, et al. Prospective study of the changes in pharmacokinetics of immunosuppressive medications after laparoscopic sleeve gastrectomy. Am J Transplant [Internet]. 2020 Feb 13;20(2):582-8. Available from: https://onlinelibrary.wiley.com/doi/abs/10.1111/ajt.15602

46. Camilleri B, Bridson JM, Sharma A, Halawa A. From chronic kidney disease to kidney transplantation: The impact of obesity and its treatment modalities. Transplant Rev [Internet]. 2016 Oct;30(4):203-11. Available from: https://linkinghub. elsevier.com/retrieve/pii/S0955470X16300271

47. Kittiskulnam P, Johansen KL. The obesity paradox: A further consideration in dialysis patients. Semin Dial [Internet]. 2019 Nov 23;32(6):485-9. Available from: https://onlinelibrary.wiley.com/doi/abs/10.1111/sdi.12834

48. Nurmohamed SA, Nubé MJ. Reverse epidemiology: paradoxical observations in haemodialysis patients. Neth J Med [Internet]. 2005 Nov;63(10):376-81. Available from: http://www.ncbi.nlm.nih.gov/pubmed/16301758

49. Hong W, Lee $\mathrm{Y}-\mathrm{J}$. The association of dialysis adequacy, body mass index, and mortality among hemodialysis patients. BMC Nephrol [Internet]. 2019 Dec 22;20(1):382. Available from: https://bmcnephrol.biomedcentral.com/articles/10.1186/ $\underline{\mathrm{s} 12882-019-1570-0}$

50. Park J, Ahmadi S-F, Streja E, Molnar MZ, Flegal KM, Gillen D, et al. Obesity Paradox in End-Stage Kidney Disease Patients. Prog Cardiovasc Dis [Internet]. 2014 Jan;56(4):415-25. Available from: https://linkinghub.elsevier.com/retrieve/pii/S0033062013001783

51. Sood A, Hakim DN, Hakim NS. Consequences of Recipient Obesity on Postoperative Outcomes in a Renal Transplant: A Systematic Review and Meta-Analysis. Exp Clin Transplant [Internet]. 2016 Apr;14(2):121-8. Available from: http://www. ncbi.nlm.nih.gov/pubmed/27015529

52. Lafranca JA, IJermans JN, Betjes MG, Dor FJ. Body mass index and outcome in renal transplant recipients: a systematic review and meta-analysis. BMC Med [Internet]. 2015 Dec 12;13(1):111. Available from: http://bmcmedicine.biomedcentral.com/articles/10.1186/s12916-015-0340-5

53. Hill CJ, Courtney AE, Cardwell CR, Maxwell AP, Lucarelli G, Veroux M, et al. Recipient obesity and outcomes after kidney transplantation: a systematic review and meta-analysis. Nephrol Dial Transplant [Internet]. 2015 Aug;30(8):1403-11. Available from: https://academic.oup.com/ndt/article-lookup/doi/10.1093/ndt/gfv214

54. Gill JS, Lan J, Dong J, Rose C, Hendren E, Johnston O, et al. The Survival Benefit of Kidney Transplantation in Obese Patients. Am J Transplant [Internet]. 2013 Aug;13(8):2083-90. Available from: http://doi.wiley.com/10.1111/ajt.12331

55. Nicoletto BB, Fonseca NKO, Manfro RC, Gonçalves LFS, Leitão CB, Souza GC. Effects of Obesity on Kidney Transplantation Outcomes. Transplantation [Internet]. 2014 Jul;98(2):167-76. Available from: http://journals.Iww.com/00007890201407270-00010

56. Yemini R, Nesher E, Carmeli I, Winkler J, Rahamimov R, Mor E, et al. Bariatric Surgery Is Efficacious and Improves Access to Transplantation for Morbidly Obese Renal Transplant Candidates. Obes Surg [Internet]. 2019 Aug 27;29(8):2373-80. Available from: http://link.springer.com/10.1007/s11695-019-03925-1

57. Kassam A, Mirza A, Kim Y, Hanseman D, Woodle ES, Quillin RC, et al. Long-term outcomes in patients with obesity and renal disease after sleeve gastrectomy. Am J Transplant [Internet]. 2020 Feb 16;20(2):422-9. Available from: https:// onlinelibrary.wiley.com/doi/abs/10.1111/ajt.15650

58. Kim Y, Bailey AJ, Morris MC, Kassam A-F, Shah SA, Diwan TS. Kidney transplantation after sleeve gastrectomy in the morbidly obese candidate: results of a 2-year experience. Surg Obes Relat Dis [Internet]. 2020 Jan;16(1):10-4. Available from: https://linkinghub.elsevier.com/retrieve/pii/S1550728919310068

59. Kassam A, Mirza A, Kim Y, Hanseman D, Woodle ES, Quillin RC, et al. Long-term outcomes in patients with obesity and renal disease after sleeve gastrectomy. Am J Transplant [Internet]. 2020 Feb 16;20(2):422-9. Available from: https:// onlinelibrary.wiley.com/doi/abs/10.1111/ajt.1565 